\title{
Reaching Consensus on Organ Donation
}

On July 20, 2016, IIIT held a forum entitled "Reaching Consensus on Organ Donation," in collaboration with the Washington Regional Transplant Community (WRTC; http://www.beadonor.org), to hear presentations by medical professionals, community leaders, religious scholars, and social scientists. Each of the four panels was followed by a robust Question and Answer session.

Panel 1: Conceptual Framework. Lori Bingham (president and CEO, WRTC) outlined the organ donation process in terms of which organizations and partners are involved, how medical suitability is determined, consulting with the surviving members, and deciding who receives the available organ. After listing the agencies and the high degree of regulation involved, she thanked Imam Johari Abdul-Malik (outreach director, Dar al-Hijrah Islamic Center) for his help in reaching out to area Muslims, some of whom decline to donate their organs on religious grounds.

Muzammil Siddiqi (chairman, Fiqh Council of North America) said that such decisions require ijtihād, for there are no relevant Qur'anic verses or hadiths. Although widely accepted by jurists, questions remain, such as which organs can be donated, should this be encouraged before or after death, can a family donate an organ if the deceased died without a will, does donating "deform" the body, how is death determined, is the patient obliged to receive it, can he/she buy it or should it be made available for free, and so on.

In his "Organization of Islamic Legal Ethics."Abdulzziz Sachedina (professor and IIIT Chair in Islamic Studies, George Mason University) stated that the main issue is procuring organs, a topic surrounded by "cultural impediments and religious misunderstandings." People are asking to whom does the body belong (the person or God), can one donate that which will not grow back, and if the donated organ will be returned on the Day of Judgment. As this is a modern issue, imams and scholars need to identiy ethical grounds in 
the Qur'an and Sunnah, namely, that which is permissible. After explaining how juridical and ethical decisions are reached, he remarked that the desired goal is a recommendation formulated by a team of experts that can be revised, as opposed to a fatwa, for that accommodates the peoples' emotions as well as the opinions of on-site specialists and others. He also listed other elements: altruism, the lack of social justice, "human beings are human beings," and that modern scientific and other advances have rendered some traditional fatwas obsolete. But in every case, the rights and decisions of the people directly involved must be respected and honored.

Abubaker A-Shingeiti (executive director, IIIT) moderated the panel.

Panel 2: Islamic Viewpoints. Ilham Altalib (chairwoman, Ikram - Foundation for the Empowerment of Muslim Women) stated that neurologic (i.e., brain), as opposed to circulatory (i.e., heart) death is considered death. Focusing on the spiritual side of this event, she mentioned that only the "soul" tastes death (Q. 3:185) and enables the body to function, that the body is only a covering for the soul, and that is to be respected and buried so that it will not be polluted. However, there is no need to worry about it being resurrected in a deformed state, for at that time each soul will receive a new body. As the Qur'an and Sunnah do not expressly forbid it, it should be made a priority in the interest of being more humanistic and to love others as you love yourself. In short, the soul has nothing to do with life and death.

Jasser Auda (Al-Shatibi Chair of Maqasid Studies, International Peace College, South Africa) spoke on his reservations as regards organ transplantation. Asserting that legal precedents, social realities, and other factors do not determine the truth, he stated that the underlying sentiment of organ donation is that people do not own their body. After pointing out that all Islamic legal schools have ruled that selling one's body is a major sin, he mentioned that that doing so is now a huge business in Africa, and that the vast majority of "donors" in Saudi Arabia and the Gulf are migrant workers who need the money in order to live. Regardless of any fatwa on the practice, he declared that on-the-ground realities need to be considered.

He then raised several issues. A brain-dead person can still be considered alive, so how can any vital organ, like the heart, be removed? How does one determine the time of death - when the brain dies or when the heart is removed? The various fiqh councils have not yet ruled on this matter. In Europe, he said that they are more skeptical about brain death. And what about someone who is comatose, for he/she might appear to be dead but is actually still alive? He closed by saying that the belief that the body is a "trust," and therefore not "owned," is very common among the Arab masses. 
Jamal Badawi (Executive Council member, Fiqh Council of North America), confined his remarks to noting that there is a huge ongoing debate over brain death itself. He was followed by Imam Johari Abdul-Malik (outreach director, Dar al-Hijrah Islamic Center), who called for formulating "standard of practice" guidelines so that imams can advise the family both correctly and intelligently. He commented that our focus should be restricted to North America, for this is where we live, and that this restriction should be stated clearly. According to him, the most pressing needs are formulating a framework for ethical consultations, the availability and accessibility of resources, new (perhaps even online) institutions, and preparing imams and others to clarify such matters to their communities.

Ermin Sinanović (director, Research and Academic Programs, IIIT) moderated the panel.

Panel 3: Professional Perspectives. Khalid M. Khan (pediatric transplant, intestinal care and transplant, MedStar Georgetown University Center) identified the fundamental question as "What do you want for yourself?" People must not become trapped in any specific framework, even a religious one. If you ask the same question to the same people, you need to change the questions (paradigm) to get new answers. He cautioned against bringing religion into any treatment procedure, for treatment is based on science.

Esam Omeish (laparoscopic and abdominal surgeon, Alexandria, VA) advocated encouraging the "culture of giving" and for more research in both ethics and scholarship. He then discussed neurologic and circulatory death, as well as how Islam defines death. Emphasizing that both of them have universally accepted definitions, he stated that the relevant scientific data needs to be presented in a way that enables the parties involved to make a formal decision. He also noted, along with other speakers, that Muslims must be encouraged to accept organ transplantation, that leading experts must formulate a set of agreed upon set of criteria to navigate this process, and that the ultimate goal should be to provide recommendations.

Sherine Hamdy (associate professor of anthropology, Brown University) reflected upon her two years of field work in Egypt on kidney donations. She remarked that some potential recipients refused to accept the kidney because doing so might hurt the donor, political repression has placed the body under threat, that the kidney was acquired under "horrible" and maybe forced conditions, or that the body may have been subjected to experimentation. Thus the "body belongs to God" becomes a phrase of resistance. As the norm is for organs to flow from poor bodies to rich bodies, from female bodies to male bodies, and from black and brown bodies to white bodies, the popular western 
phrase "gift of life" means nothing to them. Stating that most Egyptians will die from disease, suicide, or because they are in war zones, neurologic death is very rare. She cautioned the audience that understanding these people's actual contexts must be understood before an "ethical" decision can be made.

Tahara Akmal (director of clinical pastoral education, Reading Hospital School of Health Sciences), explained why she had become a chaplain and urged imams and chaplains to familiarize themselves with the social sciences and ethics so they can really connect with their patients. In addition, she stated that all individuals have the right to expect their views to be respected.

David Klassen (chief medical officer, United Network for Organ Sharing) moderated the panel.

Panel 4: Recommendations. During this final panel, the presenters further clarified their positions and did their best to outline the steps that should be taken to mover forward. Abubaker Al-Shingieti and Elling Eidbo (CEO, Association of Organ Procurement Organizations) co-moderated the panel.

The event ended with concluding remarks made by Abdulaziz Sachedina and Melissa Greenwald, MD (Health Resources and Services Administration, director, Division of Transplantation).

Jay Willoughby

AJISS

Herndon, VA 